\title{
Incidência e severidade de hérnia das crucíferas em repolho (Brassica oleracea L. var. capitata) em solo tratado com biofertilizante tipo Bokashi
}

\author{
Incidence and severity of clubroot of crucifers in cabbage (Brassica oleracea L. var. capitata) \\ in soil treated with biofertilizer Bokashi type
}

Viviane Flaviana Condé, Deise Machado Ferreira de Oliveira e José Emílio Zanzirolani de Oliveira

Instituto Federal de Educação, Ciência e Tecnologia do Sudeste de Minas Gerais - Campus Barbacena, MG, Brasil

viviconde@yahoo.com.br; deise.oliveira@ifsudestemg.edu.br; jose.oliveira@ifsudestemg.edu.br

\section{Resumo}

A hérnia das crucíferas é a doença fúngica causadora dos maiores problemas nas áreas de produção de Brassicas. Os biofertilizantes surgem como possibilidade de manejo, destacando-se aqueles do tipo bokashi. Este trabalho teve por objetivo avaliar a incidência e a severidade da doença hérnia das crucíferas causada por Plasmodiophora brassicae W. em repolho (Brassica oleracea L. var. capitata) em solo submetido a tratamentos com doses de biofertilizante tipo bokashi. O experimento foi implantado em área naturalmente infestada por Plasmodiophora brassicae, em delineamento inteiramente casualisado com quatro tratamentos e nove repetições. Os tratamentos foram as dosagens de 0, 100, 200 e $400 \mathrm{~g}$ de bokashi/ $\mathrm{m}^{2}$. Os resultados foram submetidos ao teste de médias ScottKnott ao nível de $5 \%$ de significância, ao coeficiente de correlação de Pearson e a análise de regressão. O incremento do bokashi influenciou positivamente o desenvolvimento das plantas de repolho. Com o aumento das dosagens, houve maior desenvolvimento vegetativo. A dosagem $400 \mathrm{~g} / \mathrm{m}^{2}$ foi o tratamento que apresentou a menor incidência e severidade da doença. Contudo, novos testes são necessários para verificar efeito de doses maiores do composto orgânico no controle da doença e associação desta técnica a outros controles.

Palavras-chave: Doenças de solo; Controle alternativo; Composto orgânico; Plasmodiophora brassicae W.

\section{Abstract}

Clubroot of crucifers is fungal disease causing major problems in Brassicas production areas. Biofertilizers emerge as a possibility of management, emphasizing those of Bokashi type. This study aimed to evaluate the incidence and severity of clubroot disease caused by Plasmodiophora brassicae W. in cabbage (Brassica oleracea L. var. capitata) in soil under treatment with doses of biofertilizers type Bokashi. The experiment was established in naturally infested by Plasmodiophora brassicae, in a completely randomized design with four treatments and nine replications. The treatment dosages were 0, 100, 200 and $400 \mathrm{~g}$ Bokashi/m ${ }^{2}$. The results were analyzed by means of Scott-Knott test at 5\% significance, to Pearson correlation coefficient and the regression analysis. The increase of Bokashi positively influenced the development of cabbage plants. With increasing doses there was a greater vegetative development. Dosage $400 \mathrm{~g} / \mathrm{m}^{2}$ was the treatment that had the lowest incidence and severity of disease. However, further tests are needed to verify effect of higher doses of organic compost in disease control and association of this technique to other controls.

Keywords: Soil diseases; Alternative control; Organic compound; Plasmodiophora brassicae W. 


\section{Introdução}

Entre os volumes plantados e comercializados, o repolho é a mais importante variedade de Brassica oleracea e uma das plantas olerícolas de maior relevância nacional (SILVA et al., 2011). É uma cultura de grande importância social e econômica por envolver a mão de obra familiar para o cultivo (RESENDE, 2007). De maneira geral, as hortaliças são prejudicadas pela ocorrência de doenças. As causas de manutenção das doenças em uma área são: o cultivo intensivo e escalonado em pequenas áreas; a ocorrência de culturas que hospedam patógenos e os disseminam aos plantios mais novos (PEREIRA, 2013).

A hérnia das crucíferas, causada por Plasmodiophora brassicae W., é um dos principais problemas nas áreas produtoras de Brassica em todo o mundo (VIDAL, 2012). De acordo com PEREIRA (2013), os principais sintomas da hérnia das crucíferas na parte aérea são deficiências nutricionais e desenvolvimento retardado. As plantas atacadas murcham nas horas mais quentes do dia e retomam a turgidez nas horas mais frescas. Em algumas situações, as folhas ficam com uma coloração verde mais pálido ou amarelecem. O sintoma característico (Figura 1) é a formação de galhas nas raízes, provenientes da rápida multiplicação e crescimento exagerado das células induzidas pelo patógeno. Segundo REIS (2009), as galhas variam de tamanho podendo medir desde alguns milímetros até mais de $10 \mathrm{~cm}$ de comprimento.

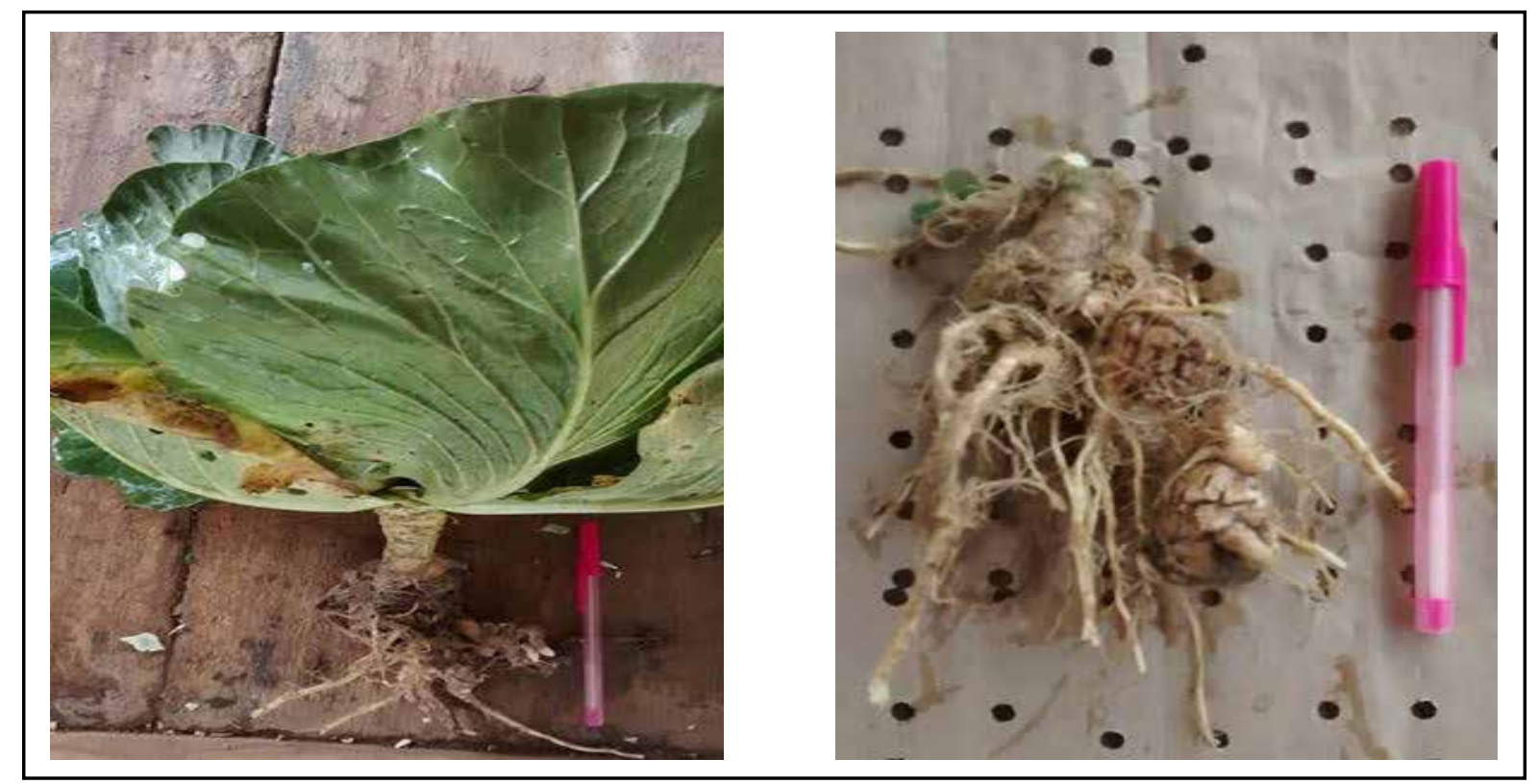

Figura 1 - Planta de repolho (a esquerda); Raiz de repolho com sintoma característico de hérnia das crucíferas (a direita)

Uma das possíveis formas de manutenção das plantas saudáveis no ambiente é utilizando fontes nutritivas adequadas. Pesquisas têm sido realizadas a fim de desenvolver alternativas aos agroquímicos no controle dos patógenos em hortaliças (PEREIRA, 2013). Os adubos orgânicos têm sido propostos ao cultivo por serem fontes de macro e micronutrientes; por melhorarem a capacidade de retenção de água, a microflora e a estabilização da estrutura dos solos. Além dos nutrientes, a adubação orgânica libera ácidos húmicos, os quais estimulam a capacidade de absorção do fósforo. Esses fatores estariam ligados à melhoria do estado de proteossíntese das plantas e consequentemente à tolerância às pragas e doenças (NETO, 2011). Uma forma de adubação é a obtida por compostos que utilizam resíduos da propriedade, denominados como biofertilizantes. Um biofertilizante que pode ser obtido facilmente e testado é o bokashi (MAGRINI et al., 2011).

$\mathrm{O}$ trabalho desenvolvido foi o de testar os efeitos do uso de bokashi em uma área sabidamente contaminada com a hérnia das crucíferas. Esta área é no Núcleo de Agricultura do Instituto Federal de Educação, Ciência e Tecnologia do Sudeste de Minas Gerais - Campus Barbacena e a espécie testada foi o repolho, por ser possível detectar morfologicamente a infestação e ser um produto que deve ter boa aparência, pelo uso in natura.

Este trabalho teve por objetivo avaliar a incidência e severidade da doença hérnia das crucíferas causada por Plasmodiophora brassicae W. em repolho (Brassica oleracea var. capitata) em solo submetido a tratamentos com biofertilizante tipo bokashi. 


\section{Material e método}

Localizado a $21^{\circ} 13^{\prime} 33^{\prime \prime} \mathrm{S}$ e $43^{\circ} 46^{\prime} 25^{\prime \prime} \mathrm{W}$, o município de Barbacena- MG possui altitude média de $1100 \mathrm{~m}$, com área de 759,186 $\mathrm{Km}^{2}$. O clima segundo a classificação de Koopen é do tipo tropical de altitude Cwb com invernos frios e verões amenos (IBGE, 2014). O trabalho foi conduzido no Instituto Federal de Educação, Ciência e Tecnologia do Sudeste de Minas Gerais - Campus Barbacena, nas instalações do Núcleo de Agricultura - NA, em uma área já infestada por Plasmodiophora brassicae. As dosagens foram de 0, 100, 200 e $400 \mathrm{~g}$ de bokashi $/ \mathrm{m}^{2}$. Os tratamentos foram aplicados em duas etapas, sendo a primeira com $75 \%$ da dosagem incorporada ao solo e $25 \%$ da dosagem 30 dias após transplantio. A lavoura de repolho foi estabelecida com o transplantio das mudas. Foi utilizado o delineamento inteiramente casualisado com 4 tratamentos e 9 repetições totalizando 36 parcelas.

A captura dos microrganismos eficientes, em região de mata próximo a área experimental, foi realizada conforme a metodologia proposta por (BONFIM et al., 2011). Aproximadamente $500 \mathrm{~g}$ de arroz cozido em água não clorada e disposto em caixa vazada de madeira, coberto por fina tela em tecido de algodão. A caixa de madeira foi colocada em região de mata e coberta com camada de serapilheira. Após 20 dias o material foi descoberto e algumas colônias de microrganismos selecionadas conforme coloração. As partes com coloração cinza, marrom e preto foram descartadas. Para a ativação dos microrganismos eficientes, foi feita a distribuição do arroz em garrafas plásticas de 2 litros. Em cada garrafa foi adicionado $200 \mathrm{ml}$ de melaço e completada com água sem cloro. As garrafas foram armazenadas a sombra por 20 dias.

De acordo com RESENDE (2007), o composto de farelos tipo bokashi é produzido a partir de misturas de farelos (arroz, trigo), tortas (algodão, soja, mamona) e outros resíduos. Essa mistura é inoculada com microrganismos e submetida à fermentação aeróbica ou anaeróbica. $\mathrm{O}$ inoculante pode ser obtido na natureza (terra de mata) ou comercial (EM - Microrganismos Eficazes). Não existe só um tipo de bokashi com receitas padronizadas, ele deve ser elaborado com matérias-primas de fácil acesso em cada região, o que acaba reduzindo os custos de produção (SIQUEIRA, 2013). Para a fabricação do bokashi deve-se fazer a homogeneização da solução na mistura de farelos. A fermentação pode ser feita de forma aeróbica ou anaeróbica. Para o experimento, optou-se por produzir o bokashi anaeróbico, com base na metodologia de produção proposta por (SIQUEIRA, 2013). Utilizou-se para o preparo do composto anaeróbico de farelos: $480 \mathrm{Kg}$ de cama de matrizes de aves, $40 \mathrm{Kg}$ de calcário dolomítico, $100 \mathrm{Kg}$ de torta de mamona, $120 \mathrm{Kg}$ de farelo de trigo, $50 \mathrm{Kg}$ de farinha de ossos, $10 \mathrm{Kg}$ de cinzas, 601 de água, 21 de leite, 2 1 de EM - microrganismos eficientes, 1,5 Kg de açúcar cristal. Os materiais foram misturados de forma uniforme e armazenados em sacos plástico fechados. Após fermentação, o composto ficou pronto em 20 dias.

A qualidade da muda produzida pode influenciar diretamente, de forma significativa, no desenvolvimento da planta no campo e na produtividade da cultura. Uma muda isenta de doenças e pragas, aparentemente vigorosa, torna-se uma planta mais tolerante à adversidade climática e às doenças e pragas, podendo expressar melhor o seu potencial produtivo (NUNES et al., 2007). A semeadura do repolho verde foi realizada em bandeja plástica de 200 células, com substrato comercial. Foi adicionado o substrato a bandeja e disposto uma semente em cada célula, cobertas por uma camada de substrato e molhada uniformemente. Após a germinação, as bandejas foram levadas a estufa de mudas e foram submetidas a uma ou duas irrigações de acordo com a temperatura e umidade do ambiente. As mudas permaneceram na casa de vegetação até atingiram o ponto ideal para transplante, entre 4 e 5 folhas e de 10 a $12 \mathrm{~cm}$ de altura.

Os canteiros foram preparados de maneira convencional. A necessidade de calagem e adubação foram determinadas com base na análise de solo, e realizadas conforme o manual de recomendações para o uso de corretivos e fertilizantes em Minas Gerais ( $5^{a}$ aproximação) (RIBEIRO, 1999), com base na análise de solo da área do experimento. Foram realizadas três aplicações de solução dos micronutrientes boro, zinco e molibdênio a partir do início da formação da cabeça com intervalos de 7 dias. Os tratamentos foram aplicados em duas etapas, sendo a primeira com $75 \%$ da dosagem incorporada ao solo e $25 \%$ da dosagem 30 dias após transplantio, aplicada em cobertura. Foi realizado o transplante das mudas de forma manual com espaçamento de $40 \mathrm{~cm}$ entre plantas e $70 \mathrm{~cm}$ entre fileiras.

A colheita das parcelas, aos 105 dias após transplantio das mudas, momento em que a maioria das parcelas atingiu o ponto de colheita, apresentando cabeça compacta e folhas externas com bordas inclinando iniciando o desprendimento. Para avaliação dos tratamentos foram observados os seguintes dados:

- Massa da matéria fresca da parte aérea (MF): após a colheita as plantas foram pesadas individualmente e obteve-se o valor em gramas.

- Massa da matéria seca (MS): as plantas já pesadas foram levadas a estufa com circulação de ar a $75{ }^{\circ} \mathrm{C}$ por 36 horas. O peso final foi avaliando obtendo-se o valor de massa seca total.

- Massa da matéria fresca das raízes (MF raiz): no momento da colheita, o repolho foi suavemente retirado do solo de forma a reduzir danos ao sistema radicular. As raízes foram pesadas individualmente e obteve-se o valor em gramas.

- Massa da matéria seca das raízes (MS raiz): as raízes foram lavadas para retirada do excesso de solo e le- 
vadas a estufa com circulação de ar a $75^{\circ} \mathrm{C}$ por 36 horas. $\mathrm{O}$ peso final foi avaliando obtendo-se o valor de massa seca total das raízes.

- Diâmetro da cabeça de repolho (D): Foi avaliado diâmetro transversal, com auxílio de uma régua, expresso em centímetros.

- Incidência da doença hérnia das crucíferas: com a observação das raízes, foi realizado diagnóstico desta variável qualitativa. Em presença de hérnia, a parcela recebeu nota 1 e em ausência nota 0 .

- Severidade da doença hérnia das crucíferas: na presença da doença as raízes foram classificadas conforme escala de severidade proposta por (J. C. S. CRUZ e NAKATANI, 2008)

Os dados coletados foram submetidos a análise de variância. As médias das variáveis quantitativas foram comparadas pelo teste de Regressão. Para as médias das variáveis qualitativas foi utilizado o teste de Scott-Knott a nível de 5\% de significância utilizando o software SISVAR (FERREIRA, 2003). Para as relações entre caracteres foram calculados os coeficientes de correlação de Pearson entre as variáveis.

\section{Resultados e discussão}

De acordo com a análise de variância, houve diferenças estatísticas significativas entre os tratamentos. A partir desta conclusão foram realizados os testes estatísticos Scott-Knott, Regressão e correlação de Pearson.

O teste de médias de Scott-Knott apresenta como vantagem separar as médias em grupos discretos, sem sobreposição entre grupos (CANTERI et al., 2001). Na tabela 1, há o comparativo das médias obtidas nas variáveis analisadas. Durante o experimento, foi constatada a incidência de podridão-mole (Pectobacterium carotovorum) na área podendo, portanto, ser considerada uma fonte de variação do experimento. Pelo resultado tem-se que a variável podridão mole apresentou diferenças, no tratamento $400 \mathrm{~g} / \mathrm{m}^{2}$ não houve incidência desta doença. As análises não apresentam diferenças estatísticas significativas com relação a incidência da doença hérnia das crucíferas. Entretanto, a variável severidade apresentou diferenças estatísticas, sendo que a dosagem $400 \mathrm{gm}$ apresentou uma menor severidade.

Tabela 1 - Avaliação da podridão mole, incidência de hérnia e severidade com relação aos tratamentos. Teste

Scott-Knott a 5\% de significância. Valores seguidos pela mesma letra não diferem estatisticamente entre si

\begin{tabular}{|c|c|c|c|}
\hline $\begin{array}{c}\text { Doses de } \\
\text { bokashi }\left(\mathrm{g} / \mathrm{m}^{2}\right)\end{array}$ & $\begin{array}{c}\text { * Podridão } \\
\text { mole }\end{array}$ & $\begin{array}{c}\text { * incidência de } \\
\text { hérnia }\end{array}$ & *Severidade \\
\hline 0 & $0,22^{b}$ & $0,66^{a}$ & $2,00^{\mathrm{b}}$ \\
\hline 100 & $0,33^{b}$ & $0,77^{a}$ & $2,00^{\mathrm{b}}$ \\
\hline 200 & $0,33^{\mathrm{b}}$ & $0,88^{\mathrm{a}}$ & $3,00^{c}$ \\
\hline 400 & $0,00^{a}$ & $0,77^{a}$ & $1,11^{a}$ \\
\hline
\end{tabular}

$\mathrm{O}$ pH do solo foi corrigido com calcário a fim de atingir valor de 6,5 e saturação de bases a $70 \%$. De acordo com (RUARO et al., 2010), a doença é mais severa em pH menores que 5,7; entre 5,7 e 6,2 a severidade da doença decresce e acima de $\mathrm{pH}$ 7,8 o patógeno é complemente inibido.

A análise de correlação avalia o grau de associação entre as variáveis (LIMA e LIMA, 2014). O coeficiente de correlação de Pearson mede o grau de correlação linear entre duas variáveis. De acordo com (FILHO e JÚNIOR, 2010), este coeficiente é um índice adimensional que varia entre os valores -1 e 1 . Normalmente, o coeficiente de correlação de Pearson é designado pela letra $\mathrm{R}$ e definido pela seguinte fórmula:

$$
r=\frac{\sum\left(x_{i}-\bar{x}\right)\left(y_{i}-\bar{y}\right)}{\sqrt{\left(\sum\left(x_{i}-\bar{x}\right)^{2}\right)\left(\sum\left(y_{i}-\bar{y}\right)^{2}\right)}}
$$

- $r=1$ significa uma correlação perfeita positiva entre as duas variáveis

- $r=0$ (zero) significa que as duas variáveis são independentes linearmente uma da outra, não há relação linear

- $r=-1$ indica uma relação linear perfeita mas inversa, isto é, com o aumento de uma variável a outra sempre diminui. Quanto mais próximo estiver de 1 ou -1, mais forte é a associação linear entre as duas variáveis, portanto:

- $\quad$ 0,6 para mais ou para menos indica uma forte correlação. 
- 0,35 a 0,6 positivo ou negativo indica correlação moderada.

- 0 a 0,35 fraca correlação, seja ela positiva ou negativa

De acordo com os resultados apresentados na figura 2, pode-se destacar que existe uma forte correlação positiva $(0,9)$ entre as variáveis matéria seca (MS) e diâmetro (D), o que indica que com o aumento do acúmulo de matéria seca há um aumento do diâmetro das cabeças de repolho. Entre as variáveis \% matéria seca das raízes (\%MS raiz) e severidade (S) houve uma correlação negativa forte $(-0,7)$, indicando que quanto mais grave o nível de severidade menor o acúmulo de matéria seca nas raízes. As variáveis Incidência de hérnia $(\mathrm{IH})$ e severidade $(\mathrm{S})$ apresentaram correlação positiva forte com valor de 0,7 , o que leva a acreditar que com o aumento da incidência há um proporcional aumento da severidade da doença hérnia das crucíferas.

\begin{tabular}{|c|c|c|c|c|c|c|c|c|c|c|}
\hline & MF (g) & MS (g) & $\% M S$ & $\begin{array}{c}\mathrm{MF} \\
\text { raiz(g) }\end{array}$ & $\begin{array}{c}\text { MS } \\
\text { raiz(g) }\end{array}$ & $\begin{array}{c}\% \mathrm{MS} \\
\text { raiz }\end{array}$ & $\mathrm{D}$ & $\mathrm{PM}$ & H & $s$ \\
\hline MF (g) & - & 0,8 & $-0,6$ & 0,3 & 0,5 & 0,2 & 0,7 & $-0,4$ & $-0,3$ & $-0,4$ \\
\hline MS (g) & & - & $-0,2$ & 0.5 & 0,7 & 0,1 & 0,9 & $-0,3$ & $-0,1$ & $-0,3$ \\
\hline$\% M S$ & & & - & $-0,1$ & $-0,1$ & 0,1 & $-0,2$ & 0,1 & 0,4 & 0,2 \\
\hline MF raiz $(\mathrm{g})$ & & & & - & 0,9 & $-0,5$ & 0,4 & 0,2 & 0,3 & 0,4 \\
\hline MS raiz $(g)$ & & & & & - & $-0,1$ & 0,6 & 0,0 & 0,2 & 0,1 \\
\hline$\%$ MS raiz & & & & & & - & 0,0 & $-0,5$ & $-0,4$ & $-0,7$ \\
\hline D & & & & & & & - & $-0,3$ & $-0,1$ & $-0,4$ \\
\hline PM & & & & & & & & - & 0,3 & 0,6 \\
\hline $\mathbf{H}$ & & & & & & & & & - & 0,7 \\
\hline $\mathrm{s}$ & & & & & & & & & & - \\
\hline
\end{tabular}

Figura 2 - Coeficiente de correlação de Pearson para as variáveis: massa da matéria fresca da parte aérea (MF); massa da matéria seca da parte aérea (MS); percentual de massa da matéria seca da parte aérea (\%MS); massa da matéria fresca das raízes (MS raiz); massa da matéria seca das raízes (MS raiz); percentual de massa da matéria seca das raízes (\%MS raiz); diâmetro das cabeças de repolho (D); incidência da doença podridão mole (PM); incidência da doença hérnia das crucíferas (IH); severidade da doença hérnia das crucíferas (S). Teste Scott-Knott a 5\% de significância. Valores seguidos pela mesma letra não diferem estatisticamente entre si

Ao realizar o teste de correlação de Pearson entre as variáveis quantitativas e os tratamentos observa-se que a correlação entre doses de bokashi e as variáveis matéria fresca, matéria seca, matéria fresca das raízes, matéria seca das raízes e diâmetro apresentaram valores de r próximos a 1 (figuras 3 a 7). A correlação existente entre os valores de massa de matéria fresca e doses de bokashi apresentou grau de associação de $97 \%$ o que indica correlação positiva forte.

A correlação entre os valores de massa de matéria seca e doses de bokashi (figura 3), apresentou grau de associação de $99 \%$ o que indica correlação positiva forte, ou seja, com o aumento da dosagem do bokashi há um incremento no teor de massa seca. Entre os valores de massa de matéria fresca das raízes e doses de bokashi (figura 4), os resultados apresentam uma correlação positiva forte superior a $99 \%$.

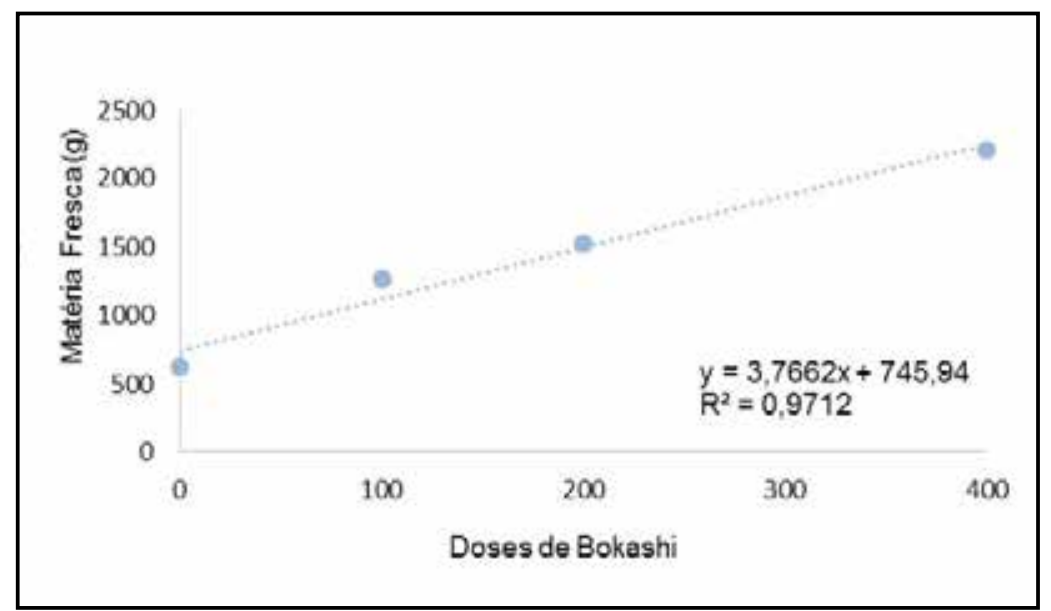

Figura 3 - Correlação entre os valores de massa de matéria fresca das cabeças de repolho e doses de composto orgânico tipo bokashi 


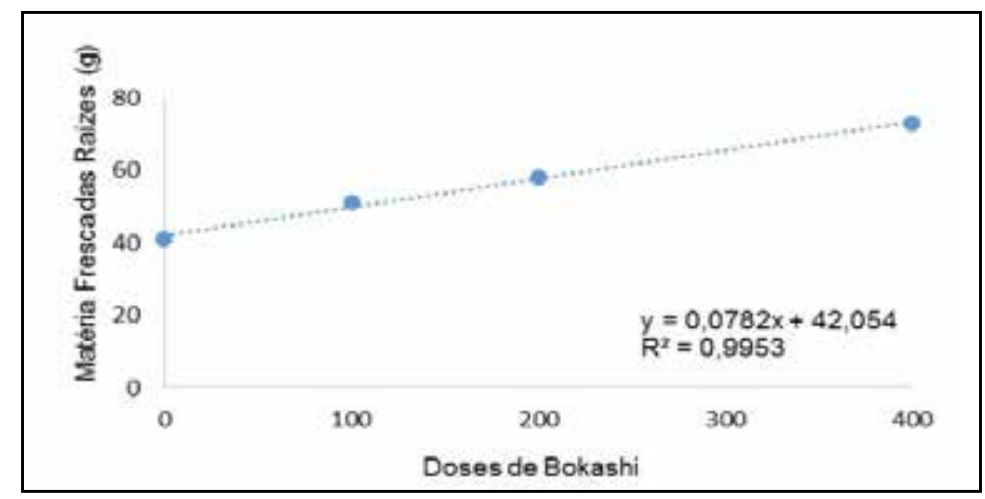

Figura 4: Correlação entre os valores de massa de matéria seca das cabeças de repolho e doses de composto orgânico tipo bokashi.

Para os valores de massa de matéria seca das raízes e doses de bokashi (figura 5), os resultados apresentam uma correlação positiva forte superior a $94 \%$.

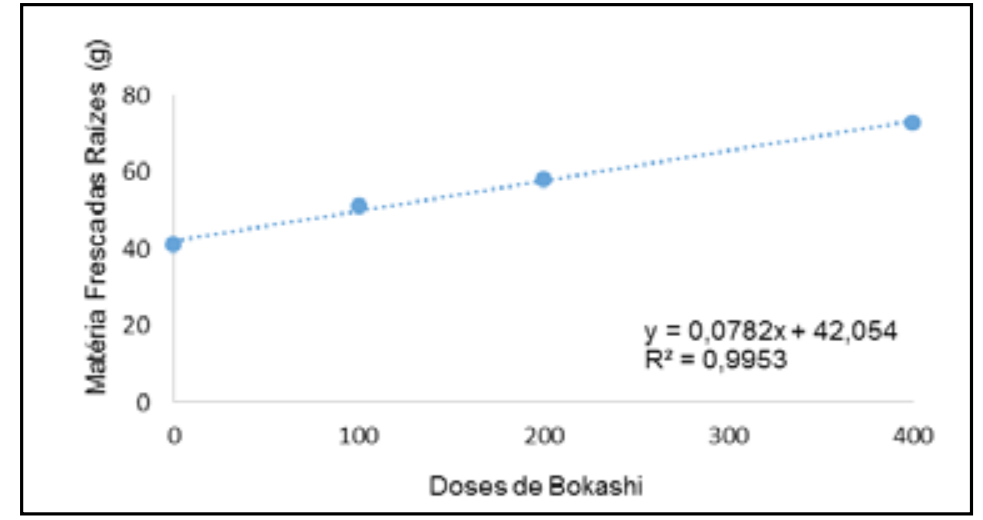

Figura 5: Correlação entre os valores de massa de matéria fresca das raízes de repolho e doses de composto orgânico tipo bokashi

Tal como a análise de correlação, a regressão linear simples é uma técnica usada para explorar a natureza da relação entre duas variáveis aleatórias contínuas. A diferença primária entre esses dois métodos analíticos é que a regressão nos possibilita investigar a mudança em uma variável chamada resposta, correspondente à mudança na outra, conhecida como variável explicativa.

A análise de correlação não faz essa distinção; as duas variáveis envolvidas são tratadas simetricamente. O objetivo máximo da análise de regressão é prever ou estimar o valor da resposta associada com um valor fixo da explicativa (PAGANO e GAUVREAU, 2004).

A análise de regressão consiste em obter uma função que explique a relação entre variáveis dependentes e independentes. A regressão linear simples consiste em utilizar o modelo estatístico linear do $1^{\circ}$ grau para explicar a relação entre duas variáveis (LIMA e LIMA, 2014)

De acordo com a análise de regressão linear simples, observou-se um efeito significativo positivo para a dosagem de bokashi. As variáveis em estudo apresentam coeficiente de determinação $\left(R^{2}\right)$, próximos a 1 . O $R 2$ varia entre 0 e 1 , indicando, em percentagem, o quanto o modelo consegue explicar os valores observados. Para matéria fresca $97 \%$ da variável dependente consegue ser explicada pelos repressores presentes no modelo (figura 8).

O modelo matemático explica em $99 \%$ a relação entre as variáveis doses de bokashi e massa de matéria seca da parte aérea do repolho (figura 9).

Quanto aos dados matéria fresca das raízes, o modelo apresenta um coeficiente de determinação de $94 \%$ (figura 10). Pode-se observar que o $R^{2}$ da variável matéria seca das raízes, aproximou-se de $100 \%$ (figura 11).

Para o efeito das doses de bokashi em relação ao diâmetro das cabeças (figura 12), observa-se no ajuste dos dados a uma regressão linear crescente, apresentando um coeficiente de determinação de 95\%.

Pode-se observar um aumento significativo da produtividade com o aumento da dosagem de bokashi. JÚNIOR e VENZON (2007) ressaltam que as hortaliças pertencem ao grupo de culturas que apresentam respostas positivas, tanto em produtividade como em qualidade de produto, quando submetidas à adubação orgânica.

De acordo com NETO (2011), a adubação orgânica libera ácidos húmicos, os quais estimulam a capacidade de absorção do fósforo. Esses fatores estariam ligados à melhoria do estado de proteossíntese das plantas e consequentemente à tolerância às pragas e doenças. 


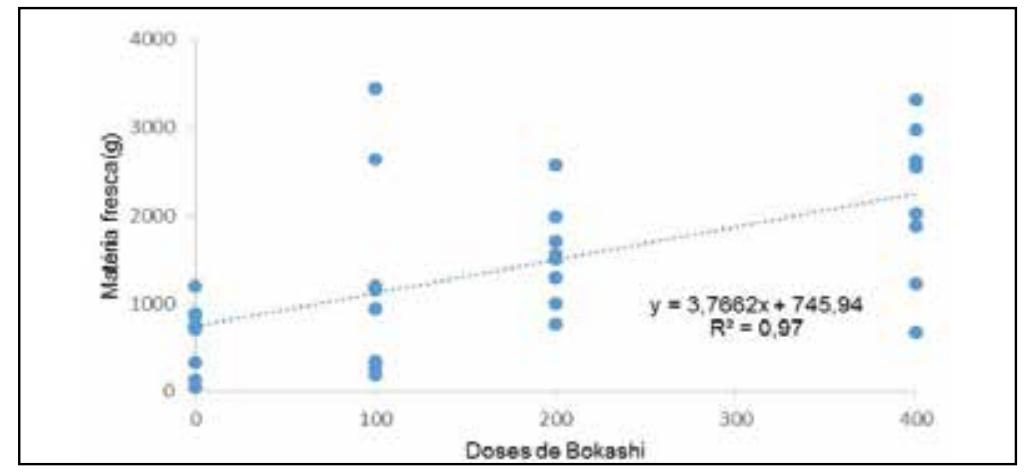

Figura 8 - Relação entre os valores de massa de matéria fresca das cabeças de repolho e doses de composto orgânico tipo bokashi

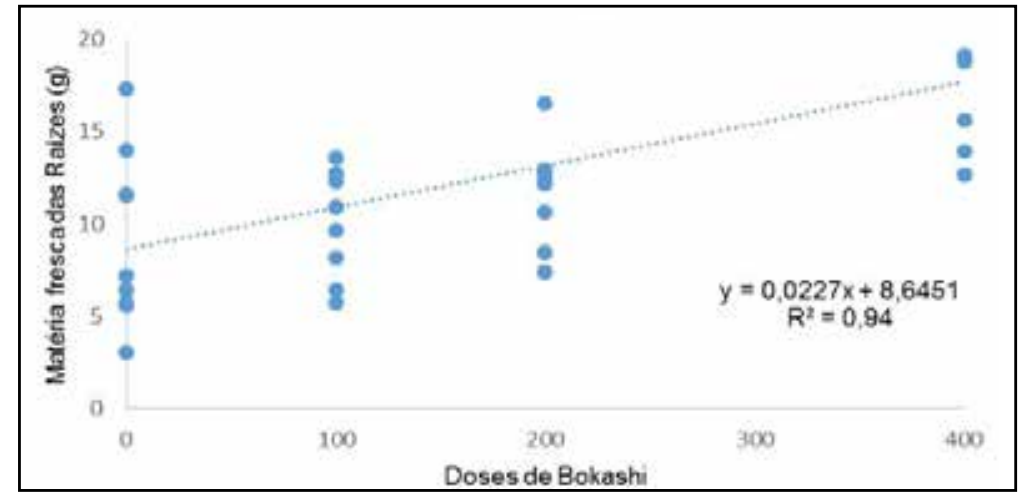

Figura 9 - Relação entre os valores de massa de matéria seca das cabeças de repolho e doses de composto orgânico tipo bokashi

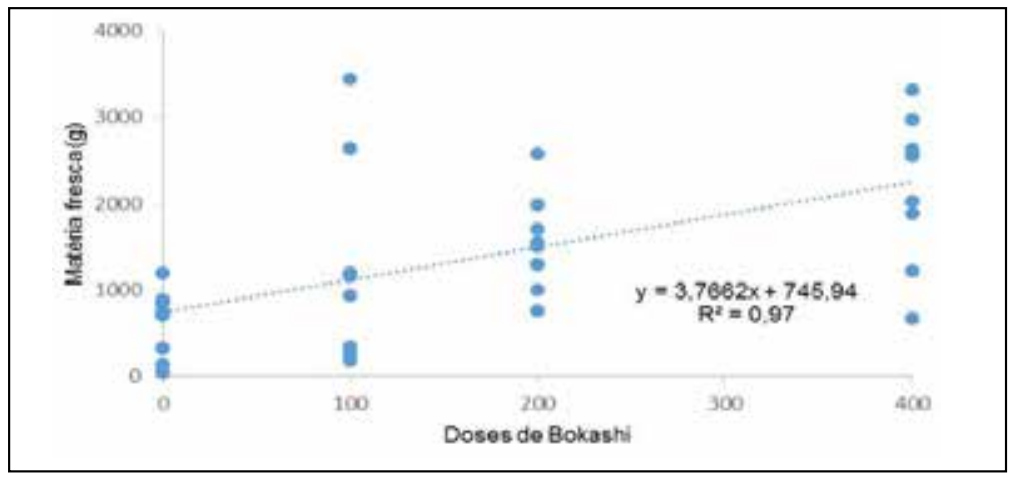

Figura 10 - Correlação entre valores diâmetro das cabeças de repolho e doses de comporto orgânico tipo bokashi

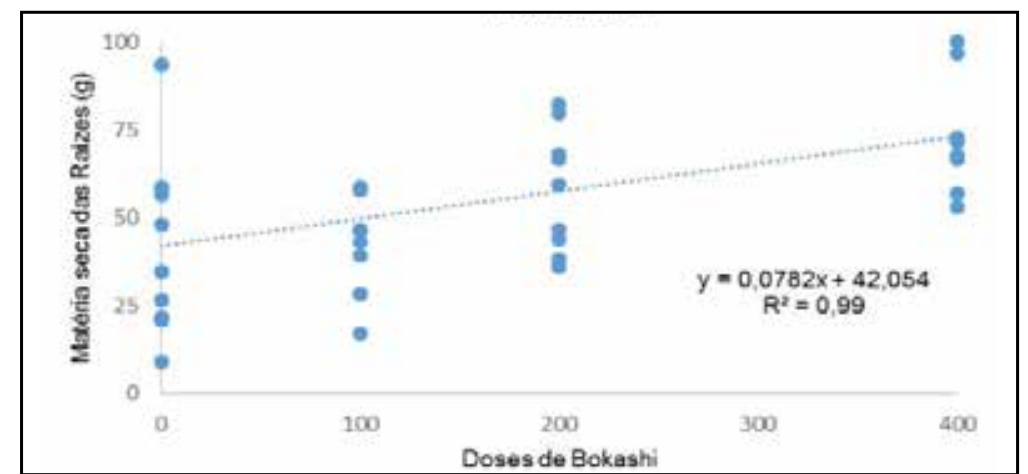

Figura 11 - Relação entre os valores de massa de matéria fresca das raízes de repolho e doses de composto orgânico tipo bokashi 


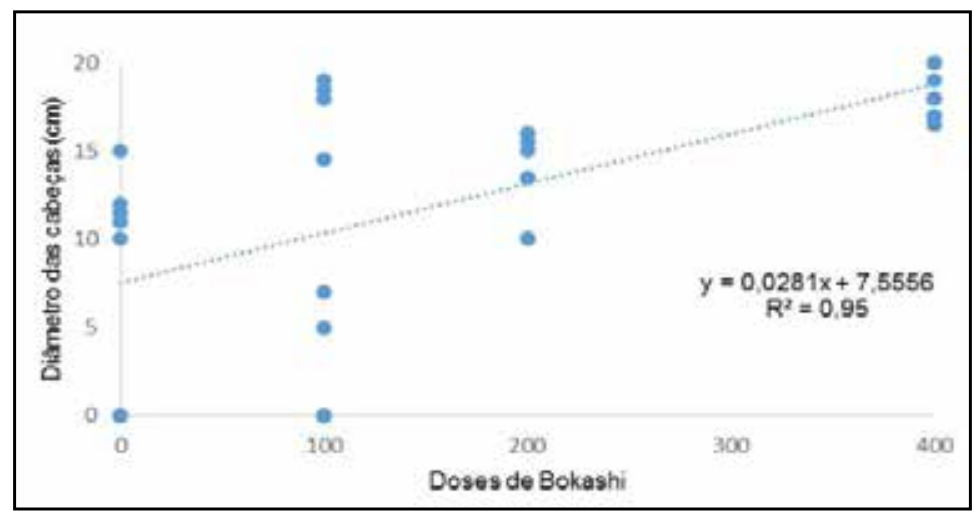

Figura 12- Relação entre os valores de diâmetro das cabeças de repolho e doses de composto orgânico tipo bokashi

\section{Conclusões}

O incremento do bokashi influenciou positivamente o desenvolvimento das plantas de repolho, ou seja, com o aumento das dosagens de bokashi houve maior desenvolvimento vegetativo das plantas.

A dosagem $400 \mathrm{~g} / \mathrm{m}^{2}$ foi o tratamento que apresentou a menor incidência da hérnia das crucíferas e a menor severidade. Durante o experimento, foi constatada a incidência de podridão-mole (Pectobacterium carotovorum) na área podendo, portanto, ser considerada uma fonte de infestação e que também foi combatida pelo bokashi.

\section{Referências}

BONFIM, F., HONÓRIO, I., REIS, I. (2011). Caderno dos Microrganismos Eficientes (EM): Instruções práticas sobre uso ecológico e social do EM. Universidade Federal de Viçosa.

CANTERI, M. G., ALTHAUS, R., FILHO, J. D. V. (2001). Sasmagri: Sistema para análise e separação de médias em experimentos agrícolas pelos métodos Scott-knott, Tukey e Duncan. Revista Brasileira de Agrocomputação, v. 1, n. 2, p. 18-24.

CRUZ, J. C. S., NAKATANI, A. N. (2008). Caracterização patogênica e molecular de Plasmodiophora brassicae. Tropical Plant Pathology, p. 415-424.

FILHO, D. B. F., JÚNIOR, J. S. (2010). Desvendando os mistérios do coeficiente de correlação de pearson (r). Revista Política Hoje, v. 18, n. 1, p.116-146.

IBGE (2014). Nota 1: estimativa da população residente com data de referência 1o de julho de 2014. Diário oficial da União em 28/08/2014.

JÚNIOR, T. J. D. P., VENZON, M. (2007). 101 culturas: manual de tecnologia agrícola. EPAMIG.

LIMA, P.C., LIMA, R.R. (2014). Estatística Experimental. Guia de Estudos. Universidade Federal de Lavras., v. 20, n. 06, p. $7-184$.

MAGRINI, F., SARTORI, V., FINKLER, R. (2011). Características químicas e avaliação microbiológica de diferentes fases de maturação do biofertilizante bokashi. Agrarian, v. 4, n. 12, p 146-151.

NETO, D. D. (2011). A teoria da trofobiose. Escola superior de agricultura “Luiz de Queiroz" Departamento de produção vegetal Piracicaba SP.

NUNES, M., dos SANTOS, J., de SOUZA, R. A. (2007). Sistema de produção orgânico de repolho em consórcio com o coentro em Sergipe. Embrapa Tabuleiros Costeiros Circular Técnica. 
PAGANO, M., GAUVREAU, K. (2004). Princípios de bioestatística. Thomson learning. Thomson Learning. p. 506.

PEREIRA, R. B. (2013). Diagnose e controle alternativo de doenças em alface, alho, cebola e brássicas. Circular técnica EMBRAPA 2013.

REIS, A. (2009). Hérnia das crucíferas. Comunicado técnico 72.

RESENDE, F. V. (2007). Cultivo do alface em sistema orgânico de produção. Embrapa Hortaliças.

RIBEIRO, A. C. (1999). Recomendações para o uso de corretivos e fertilizantes em Minas Gerais: 5. Aproximação. Comissão de fertilidade do solo do estado de Minas Gerais.

RUARO, L., NETO, V., MOTTA, A. (2010). Efeito do pH do solo em diferentes níveis de concentração de inóculo de controle de Plasmodiophora brassicae. Summa Phytopathol., v36., p. 16-20.

SILVA, G. D., FILHO, A. C., BARBOSA, J. (2011). Espaçamentos entrelinhas e entre plantas no crescimento e na produção de repolho roxo. Bragantia, v. 70, n. 03, p 538-543.

SIQUEIRA, A., SIQUEIRA, M. D. Bokashi: adubo orgânico fermentado. Niterói: Programa Rio Rural. 2013

VIDAL, M. C. (2012). Métodos tradicionais de controle da hérnia das crucíferas. Embrapa Hortaliças Brasília, DF. 